\title{
Mulheres em municípios no Uruguai: o perfil, a trajetória e as experiências das alcaldesas e concejalas eleitas no país (2010-2015)
}

Rosangela Marione Schulz e Marina dos Santos Landa

\author{
Rosangela Marione \\ Doutora em Ciência Política pela Universidade Federal do Rio Grande \\ do Sul (2003). Atualmente é professora associada da Universidade \\ Federal de Pelotas. Tem experiência na área de Ciência Política, com \\ ênfase em Democracia e Representação. \\ Email: rosangelaschulz@gmail.com \\ ORCID: https://orcid.org/0000-0001-8820-5083 \\ Marina dos Santos Landa \\ Doutoranda em Ciência Política também pela Universidade Federal de \\ Pelotas pelo Programa de Pós-Graduação em Ciência Política \\ (PPGCPol). \\ Email: marinalanda@unipampa.edu.br \\ ORCID: https://orcid.org/0000-0001-9646-8916
}

\section{Resumo}

A proposta central desse artigo é analisar a experiência política das primeiras mulheres eleitas aos cargos do terceiro nível da política uruguaia (municípios), nível institucionalizado em 2010 pela Lei de Descentralização Política e Participação Cidadã. A partir dos resultados eleitorais e dos dados coletados, identificou-se que 22 mulheres foram eleitas para o cargo de Alcaldesa e outras 66 para o cargo de Concejala (em um universo de 89 e 356 cargos em disputa, respectivamente), isto é, aproximadamente $20 \%$ das vagas, dentre os dois cenários. Em pesquisa de campo realizada no Uruguai foram entrevistadas quinze representantes em quatro Departamentos (Montevidéu, Canelones, Rocha e Cerro Largo). O artigo está dividido nos seguintes pontos: 1 . Notas metodológicas que apresentam o desenho da pesquisa de campo; 2. O processo de municipalização; 3. Análise das entrevistas, destacando o perfil, as trajetórias e experiências das representantantes eleitas para os Conselhos Municipais uruguaios no pleito de 2010. Por fim, algumas considerações.

\section{Palavras-chave}

Uruguai, Eleições municipais, Representação política de mulheres; Alcaldesa; Concejala

\begin{abstract}
The central purpose of this article is to analyze the politic experience of the first elected women to the third level of politic in Uruguay, level institutionalized in 2010 by the Law of Political Decentralization and Citizen Participation. From the electoral results and the data collected, it was identified that 22 women were elected for the position of Alcaldesa and another 66 for the position of Concejala (in a universe of 89 and 356 positions in dispute, respectively), that is, approximately $20 \%$ of vacancies, between the two scenarios. In a field research carried out in Uruguay, fifteen representatives were interviewed in four departments (Montevideo, Canelones, Rocha and Cerro Largo). The article is divided into the
\end{abstract}


Rosangela Marione Schulz e Marina dos Santos Landa

following points: 1 . Methodological notes that present the design of the field research; 2 . The municipalization process; 3 . Analysis of the interviews, highlighting the profile, trajectories and experiences of the elected representatives for the Uruguayan Municipal Councils in the 2010 Election. Finally, some considerations.

\section{Keywords}

Uruguay, Municipal Elections, Women's Political Representation; Alcaldesa; Concejala

\section{Introdução}

Em 2010, o Uruguai somou-se aos demais países da América do Sul, ao institucionalizar o terceiro nível de governo, isto é, o nível municipal. Depois de muita discussão, 16 alterações do conteúdo original, 18 meses de tramitação, finalmente foi sancionada a Lei 18.567, de 13 de setembro de 2009, intitulada Lei de Descentralização Política e Participação Cidadã. A partir da delimitação territorial e do agrupamento de povoados e localidades, bem como da articulação dos Intendentes (Governadores), foram estabelecidas 89 municípios para o primeiro ciclo eleitoral, o qual elegeu por cinco anos os primeiros Conselheiros Municipais.

Até a criação dos municípios, institucionalmente, existiam apenas dois níveis de organização política: o primeiro nível constituído pelos poderes Executivo e Legislativo nacionaisi; o segundo nível formado por 19 Estados que integram a República Oriental do Uruguaii. Para exemplificar, Montevidéu é uma das 19 unidades que compõe a Federação, a partir da municipalização foram estabelecidos dentro do Departamento oito municípios.

A experiência municipal é uma tentativa do Estado Uruguaio de descentralizar a política nacional, caracterizada pela forte concentração decisória nas instâncias nacional e departamental (estadual). Dessa forma, ao instrumentalizar autonomia local para regiões que anteriormente eram apenas povoados e ao estabelecer a eleição de autoridades locais, a expectativa do Estado é que amplie-se a participação popular e a vida política no interior do país, atualmente circunscrita à capital Montevidéu e as zonas centrais.

Vários estudos têm sido realizados com o objetivo de examinar as potencialidades e as fragilidades da fórmula municipal uruguaia: estudos sobre o teor da lei que origina os governos locais (BARRETO, 2011); sobre a geografia e distribuição dos Municípios (QUETGLES, 2011); avaliação dos resultados nacionais e por Intendências (CARNADELLO e FREIGEDO, 2011), o desempenho dos principais partidos do país e, até mesmo, sobre a percepção da população sobre as eleições (OROÑO, 2011). Nosso propósito é somar-se a essa gama de investigações, focando nos novos atores políticos eleitos, particularmente nas mulheres.

Os estudos sobre representação política das mulheres uruguaias se dedicam à análise da presença ou ausência destas no Parlamento (Johnson 2001, 2005 e 2008; Moreira 1994; Pérez 2006, 2015; Pérez e Vairo 2013; Schulz e Moritz, 2014). Apesar da importância dos municípios como canais de entrada das mulheres no campo político eleitoral, ainda são raros os estudos devotados ao tema neste novo nível de governo implementado no Uruguai (LANDA, 2015).

Através do levantamento dos dados disponíveis no site da Corte Eleitoral Uruguaia, identificamos que 22 mulheres foram eleitas para o cargo de Alcaldesa e 65 para o cargo de

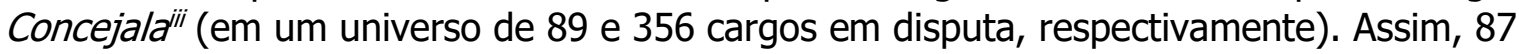


Rosangela Marione Schulz e Marina dos Santos Landa

mulheres foram eleitas para compor os Conselhos Municipaisiv, o que representa aproximadamente $20 \%$ das vagas a disposição. Especificamente, $24,7 \%$ foram eleitas como Alcaldesas e 18,2\% como Concejalas. Os números, embora comedidos, são melhores que os apresentados na instância parlamentar do mesmo períodov .

Em relação ao desempenho e a distribuição por partidos, observa-se que o Partido Nacional (PN) e a Frente Ampla (FA) foram os responsáveis por eleger a maioria das mulheres para os Conselhos Municipais. O PN elegeu 14 Alcaldesas, a FA elegeu sete, enquanto o Partido Colorado (PC) elegeu apenas uma mulher. Em relação às Concelajas, a FA elegeu 30, seguido pelo PN que elegeu 29, ficando por último, o Partido Colorado que elegeu seis representantes.

A proposta central deste artigo é compreender quem são as primeiras mulheres eleitas para compor os Conselhos Municipais do Uruguai de 2010 a 2015. Além dos dados disponíveis nas instâncias governamentais e da Corte Eleitoral, utilizamos narrativas das alcaldesas e concejalas entrevistadas durante a pesquisa de campo realizada no país. A partir destas informações, buscamos construir um perfil socioeconômico e desenhar a trajetória política e de militância das representantes uruguaias.

Neste sentido, o artigo está dividido em quatro etapas. A introdução é seguida de algumas notas metodológicas que explicam o formato da pesquisa de campo realizada no Uruguai que subsidia o artigo. O processo de municipalização será brevemente apresentado com intuito de compreender o papel dos municípios na estrutura administrativa. Por fim, apresentamos o perfil, as trajetórias e experiências das representantantes eleitas para os Conselhos Municipais no pleito de 2010, fechando com algumas considerações.

\section{Notas metodológicas}

Quanto à metodologia aplicada optamos por versar tanto por procedimentos quantitativos quanto qualitativos. Inicialmente foi mapeada a presença de mulheres na composição dos Conselhos Municipais em todos os Departamentos uruguaios. A partir dos dados descritos, para se obter um aprofundamento da situação e do cotidiano da estrutura municipal, buscou-se contatar por correio eletrônico todas as mulheres que ocupavam um cargo no Conselho Municipal, sendo entrevistadas todas aquelas que manifestaram interesse em participar da pesquisa.

A ideia inicial era entrevistar apenas alcaldesas, ou seja, aquelas que alcançaram votos suficientes para ocupar o poder Executivo. Porém, não poderíamos deixar de buscar compreender as particularidades do cargo de concejala, desta forma, incluímos algumas entrevistas com ocupantes destas vagas. Importante destacar que trata-se de um cargo não remunerado, assim enfrentamos maiores dificuldades para acessar tais representantes. Os contatos iniciais com os municípios foram feitos por telefone (ainda no Brasil), buscando agendar as entrevistas. Alguns municípios são muito pequenos e distantes da capital, que concentra a maior parte da população uruguaia, tornando inviável as entrevistas in loco. Algumas representantes contatadas não demonstraram interesse em participar da pesquisa.

Depois de um esforço significativo para acessar as representantes, as entrevistas foram realizadas no segundo semestre de 2014 com 15 mulheres que ocupavam cargo no Conselho Municipal. O grupo é composto por dez Alcaldesas e cinco Concejalas. A pesquisa abarcou quatro Departamentos do Uruguai: Montevidéu, Canelones, Rocha e Cerro Largo, atingindo 11 municípios, conforme descrito no Quadro 1. 
Rosangela Marione Schulz e Marina dos Santos Landa

Quadro 1. Representantes, Municípios e Departamentos pesquisados

\begin{tabular}{|c|c|c|}
\hline Nome e Cargo ocupado & Município & Departamento \\
\hline Beatriz Lamas (Alcaldesa) & San Ramón & Canelones \\
\hline Cristina Castro (Alcaldesa) & Progreso & Canelones \\
\hline Gletel Ferrari (Alcaldesa) & Santa Rosa & Canelones \\
\hline Graciela Echenique (Alcaldesa) & Fraile Muerto & Cerro Largo \\
\hline Rosa Imoda (Alcaldesa) & Los Cerrillos & Canelones \\
\hline Adriana Rojas (Suplente do Alcalde) & Município A & Montevidéu \\
\hline Lilián Piña ( $2^{\mathrm{a}}$ Concejala) & Município A & Montevidéu \\
\hline Cristina oliveira ( $1^{\text {a }}$ Concejala) & Município B & Montevidéu \\
\hline Míriam Rodríguez (Alcaldesa) & Município C & Montevidéu \\
\hline Sandra Nedov (Alcaldesa) & Município D & Montevidéu \\
\hline Susana Camarán (Alcaldesa) & Município E & Montevidéu \\
\hline María Elena Godoy (2a Concejala) & Município E & Montevidéu \\
\hline Teresa Nieves (4a Concelaja) & Município E & Montevidéu \\
\hline Mabel Lamadrid (Suplente do Alcalde) & Município G & Montevidéu \\
\hline Mary Urse (Alcaldesa) & Chuy & Rocha \\
\hline
\end{tabular}

Fonte: Elaboração das autoras (2020)

Todos os encontros ocorreram nos sedes administrativas dos municípios. Esse fator permitiu observar de perto a dinâmica de organização, o atendimento a população e um pouco da rotina de cada uma das entrevistadas. Para mais, as entrevistas foram realizadas no final do quarto ano de gestãovi, o que possibilitou delinear um panorama aprofundado sobre a experiência vivida por estas mulheres que, por cinco anos, estiveram à frente das primeiras administrações municipais do país. 
Rosangela Marione Schulz e Marina dos Santos Landa

As entrevistas semi-estruturadas seguem um roteiro elaborado previamente composto por três eixos centrais: (a) aspectos socioeconômicos: idade, escolaridade, estado civil, profissão, partido político; (b) aspectos da trajetória política: militância política, vínculo partidário, cargos públicos ou políticos anteriores e recrutamento eleitoral; (c) experiência administrativa frente ao governo municipal uruguaio, incluem-se neste eixo as potencialidades/fragilidades que a forma municipal impõe e expectativas da manutenção da carreira política, incluindo a reeleição.

\section{A municipalização no Uruguai}

O projeto de descentralizar e introduzir um terceiro nível de governo eletivo foi idealizado em 2009, constituindo-se como um dos objetivos do plano do primeiro governo da Frente Ampla no Uruguaivii. Depois de um ano e seis meses de tramitação, a Lei 18.567 foi sancionada, chamando-se Lei de Descentralização Política e Participação Cidadã (sendo popularmente referida pelos uruguaios como Lei de Alcaldías). Para o primeiro ciclo eleitoral foram designadas 89 localidades $(2010$ - 2015), estas foram estendidas para o número de 112 no segundo ciclo eleitoral (2010 - 2015).

Os municípios não são apenas considerados uma novidade na vida política do cidadão uruguaioviii, mas também são uma inovação em matéria de organização política a nível territorial. Ao dar centralidade para a participação cidadã torna-se uma tentativa de firmar uma relação mais próxima entre a classe política e os cidadãos, a partir do fortalecimento de uma identificação com os governantes locais. Cabe destacar que os municípios têm a obrigação de aprovar e/ou alterar seus planos de gestão em uma audiência anual através das deliberações populares aprovadas nos Cabildos Locales. Estes espaços assumem o formato de assembleias abertas, que devem ser realizadas periodicamente pelos governos municipais ${ }^{\mathrm{ix}}$.

As eleições locais possuem a particularidade de formar um Conselho Municipal ${ }^{x}$, composto por cinco pessoas, que decidem as atividades em votação conjunta, reunindo-se semanalmente para discutir os temas dos municípios. Os conselheiros são eleitos para mandatos de cinco anos. O nome mais votado da lista mais votada é o A/calde/Alcaldesa, os outros quatro são chamados de Concejales/as. As colocações são definidas proporcionalmente, conforme o desempenho das listas eleitorais pré-ordenadas pelos partidos envolvidos na disputa eleitoral.

Nesse modelo, o Alcalde/A/caldesa surge como a figura de destaque, é o responsável por decidir as votações empatadas, representa o município perante o Intendente, além de ser o único cargo remunerado. As funções dos conselheiros incluem ajudar o A/calde em suas atribuições e fiscalizar suas ações de gestor. A realização da primeira eleição abriu a possibilidade dos partidos lançarem diversas listas com os mesmos nomes, desde que em posições diferentes, dessa forma, os candidatos poderiam concorrer, ao mesmo tempo, para os dois cargos que estavam em disputa.

Apesar da expectativa, em sua primeira experiência municipal, o processo no país foi marcado por atropelos e pouco investimento partidário. Aliado a esses fatores, a falta de esclarecimento por parte do governo nacional sobre a funcionalidade do nível municipal e o desconhecimento por parte da população sobre a realização do pleito resultaram em altíssimos índices de abstenções e votos nulos (MAGRI, 2010). 
Rosangela Marione Schulz e Marina dos Santos Landa

Com esta conturbada conjuntura, Alcaldes e Concejales deram início aos seus mandatos e ao trabalho no nível municipal. O próximo ponto parte para a análise das entrevistas semi-estruturadas das representantes eleitas no pleito municipal de 2010, trazendo relatos sobre a experiência vivida pelas mulheres frente ao novos governos que se instalaram no Uruguai.

\section{Alcaldesas e concejalas. perfil, trajetória e experiência}

Dentre os resultados encontrados, o primeiro aspecto que cabe destacar é que há uma distinção muito clara entre o caminho percorrido pelas mulheres da coalizão de esquerdas (FA) e pelas mulheres de centro/direita (PN) até a eleição municipal. $O$ vínculo partidário se mostrou como tema central e determinante em todas as questões trabalhadas. Isso acontece porque o sistema partidário uruguaio é estruturado por apenas três partidos relevantes, e pragmaticamente se polarizam em dois eixos: os tradicionais - Partido Colorado e Partido Nacional e a coalizão de esquerdas - Frente Ampla.

O primeiro elemento desta análise se refere aos aspectos sociais e econômicos. 0 quadro 2 está organizada em ordem alfabética, conforme os nomes das entrevistadas. Constam informações sobre o cargo que assumiram no Conselho Municipal, o município pelo qual foram eleitas, o partido que pertencem. No tocante às informações pessoais, há detalhamentos sobre a faixa etária, a situação civil, a filiação, a escolaridade e as profissões de cada mulher.

Quadro 2. Perfil social e econômico: Alcaldesas e Concejalas (2010 - 2015).

\begin{tabular}{|l|c|c|c|c|c|c|}
\hline \multicolumn{1}{|c|}{ Nome } & Município & $\begin{array}{c}\text { Ano de } \\
\text { nasci- } \\
\text { mento }\end{array}$ & $\begin{array}{c}\text { Estado } \\
\text { Civil } \\
\text { Filhos }\end{array}$ & $\begin{array}{c}\text { Escolaridad } \\
\text { e }\end{array}$ & Profissão & Partido \\
\hline $\begin{array}{l}\text { Adriana Rojas } \\
\text { (Concejala) }\end{array}$ & Município A & 1965 & $\begin{array}{c}\text { Casada } \\
1 \text { filho }\end{array}$ & Superior & Psicóloga & FA \\
\hline $\begin{array}{l}\text { Beatriz Lamas } \\
\text { (Alcaldesa) }\end{array}$ & San Ramón & 1963 & $\begin{array}{l}\text { Casada } \\
4 \text { filhos }\end{array}$ & Superior & Dentista & PN \\
\hline $\begin{array}{l}\text { Cristina Castro } \\
\text { (Alcaldesa) }\end{array}$ & Progreso & 1951 & $\begin{array}{l}\text { Casada } \\
2 \text { filhos }\end{array}$ & Médio & $\begin{array}{c}\text { Ferroviária } \\
\text { (aposentada) }\end{array}$ & FA \\
\hline $\begin{array}{l}\text { Cristina oliveira } \\
\text { (Concejala) }\end{array}$ & Município B & 1953 & $\begin{array}{c}\text { Casada } \\
2 \text { filhos }\end{array}$ & Superior & $\begin{array}{c}\text { Secret. } \\
\text { parlamentar } \\
\text { (aposentada) }\end{array}$ & FA \\
\hline $\begin{array}{l}\text { Gletel Ferrari } \\
\text { (Alcaldesa) }\end{array}$ & Santa Rosa & 1955 & $\begin{array}{c}\text { Casada } \\
1 \text { filho }\end{array}$ & Superior & Médica & PN \\
\hline $\begin{array}{l}\text { Graciela } \\
\text { Echenique } \\
\text { (Alcaldesa) }\end{array}$ & Fuerto & 1955 & $\begin{array}{l}\text { Casada } \\
5 \text { filhos }\end{array}$ & Médio & Produtora Rural & PN \\
\hline
\end{tabular}


Rosangela Marione Schulz e Marina dos Santos Landa

\begin{tabular}{|c|c|c|c|c|c|c|}
\hline $\begin{array}{l}\text { Lilián Piña } \\
\text { (Concejala) }\end{array}$ & Município A & 1954 & $\begin{array}{l}\text { Divorciada } \\
3 \text { filhos }\end{array}$ & $\begin{array}{l}\text { Superior } \\
\text { Incompleto }\end{array}$ & $\begin{array}{c}\text { Coordenadora } \\
\text { política (FA) }\end{array}$ & $\mathrm{FA}$ \\
\hline $\begin{array}{l}\text { Mabel Lamadrid } \\
\text { (Suplente del } \\
\text { Alcalde) }\end{array}$ & Município G & 1954 & $\begin{array}{l}\text { Divorciada } \\
1 \text { filho }\end{array}$ & Fundamenta & $\begin{array}{c}\text { Operária Têxtil e } \\
\text { líder cooperativista } \\
\text { (aposentada) }\end{array}$ & FA \\
\hline $\begin{array}{l}\text { María Elena Godoy } \\
\text { (Concejala) }\end{array}$ & Município E & 1947 & $\begin{array}{l}\text { Divorciada } \\
1 \text { filho }\end{array}$ & Médio & $\begin{array}{l}\text { Operária Têxtil } \\
\text { (aposentada) }\end{array}$ & FA \\
\hline $\begin{array}{l}\text { Mary Urse } \\
\text { (Alcaldesa) }\end{array}$ & Chuy & 1954 & $\begin{array}{l}\text { Casada } \\
5 \text { filhos }\end{array}$ & $\underset{\text { I }}{\text { Fundamenta }}$ & Empresária & $\mathrm{FA}$ \\
\hline $\begin{array}{l}\text { Míriam Rodríguez } \\
\text { (Alcaldesa) }\end{array}$ & Município C & 1955 & $\begin{array}{l}\text { Divorciada } \\
3 \text { filhos }\end{array}$ & Superior & Professora & $\mathrm{FA}$ \\
\hline $\begin{array}{l}\text { Rosa Imoda } \\
\text { (Alcaldesa) }\end{array}$ & Los Cerrillos & 1961 & $\begin{array}{l}\text { Solteira } \\
\text { sem filhos }\end{array}$ & Médio & Secretária & PN \\
\hline $\begin{array}{l}\text { Sandra Nedov } \\
\text { (Alcaldesa) }\end{array}$ & Município D & 1964 & $\begin{array}{l}\text { Casada } \\
3 \text { filhos }\end{array}$ & Tecnólogo & $\begin{array}{c}\text { Metalúrgica } \\
\text { Líder Associativa }\end{array}$ & FA \\
\hline $\begin{array}{l}\text { Susana Camarán } \\
\text { (Alcaldesa) }\end{array}$ & Município E & 1966 & $\begin{array}{l}\text { Casada } \\
1 \text { filho }\end{array}$ & Médio & $\begin{array}{l}\text { Educadora pré- } \\
\text { escolar }\end{array}$ & FA \\
\hline $\begin{array}{l}\text { Teresa Nieves } \\
\text { (Concelaja) }\end{array}$ & Município E & 1951 & $\begin{array}{l}\text { Divorciada } \\
2 \text { filhos }\end{array}$ & Médio & $\begin{array}{l}\text { Professora } \\
\text { (aposentada) }\end{array}$ & FA \\
\hline
\end{tabular}

Fonte: Elaboração das autoras (2020)

Os dados demonstram que estamos diante de um perfil de mulheres "maduras", já que a mais jovem, no momento da realização das entrevistas, estava prestes a completar 50 anos. Todas possuíam idades entre 49 e 70 anos, o que demonstra uma aproximação muito grande no quesito faixa etária. Em relação ao estado civil, também encontramos um perfil uniforme entre as entrevistas. Com uma exceção, todas relataram ser ou terem sido casadas, tendo filhos e netos.

Todas entrevistadas já possuíam carreira profissional consolidada. No caso das mulheres da FA, o trabalho estava atrelado ao meio político, seja porque ocupavam cargo técnico (na estrutura burocrática política) ou por desenvolverem projetos na base sindical. São três professoras, quatro operárias, uma coordenadora política, uma secretária parlamentar, uma psicóloga e uma microempresária. As quatro mulheres ligadas ao PN possuíam profissões de cunho liberal, sendo que três em profissões tradicionais: médica, dentista e produtora rural. Apenas uma mulher do PN possuía um trabalho vinculado ao meio político: secretária parlamentar. 
Rosangela Marione Schulz e Marina dos Santos Landa

Grande parte das entrevistadas relatou já estar aposentada do trabalho, possivelmente efeito da legislação municipal, uma vez que o único cargo do Conselho Municipal a receber salário é o de Alcaldesa, como dito anteriormente, as Concejalas desempenham suas funções voluntárias. Assim, há duas maneiras de se dedicar a vida pública neste nível: a) recorrendo a uma jornada dupla de trabalho, ou seja, exercendo uma profissão que permita conciliar as duas atividades; b) sendo aposentada da carreira profissional.

Por fim, o último aspecto a ser analisado é a escolaridade. Cabe destacar que não foi possível encontrar nenhum padrão entre as entrevistadas. Há mulheres com o Ensino Superior completo, enquanto há algumas apenas com Ensino Fundamental. Dessa forma, sugere-se que, a nível municipal, esta não é uma variável determinante no sucesso eleitoral. Opondo-se aos resultados encontrados nos outros níveis de representação em diversos estudos empíricos em cargos de maior prestígio no Uruguai (JOHNSON, 2004; PÉREZ e VAIRO, 2013; SCHULZ e MORITZ, 2014).

Ao iniciarmos a análise do segundo eixo - trajetória e militância política - observamos que o vínculo com o partido é um fio condutor relevante para a condução da vida política. 0 reconhecimento a nível local é uma característica extremamente determinante para o sucesso eleitoral para as mulheres filiadas à FA. A trajetória que mais se afasta entre as frenteamplistas é de Mary Urse (FA), Alcaldesa do Município do Chuy. Urse iniciou a militância na juventude, com 18 anos, ao filiar-se ao PN, partido ao qual permaneceu até 2003. Durante esse tempo ocupou alguns cargos de confiança em governos $B l a n \cos ^{x i}$, na Intendência de Rocha. Após alguns desentendimentos, desligou-se do partido. Ficou alguns meses filiada ao PC, até que em 2004 filiou-se a FA, partido pelo qual concorreu às eleições, tornando-se Edila Locałii na magistratura 2005-2010. Em sua entrevista fez questão de destacar a trajetória e a atuação social na comunidade local. Segundo suas palavras, sua eleição é resultado do reconhecimento de trabalhos na localidade de Chuy:

\section{[...] Nosotros, el 5 de enero, cumplimos 24 años que llevamos presentes a todos los niños carenciados de Chuy, como 1200 niños, lo venimos trabajando hace 24 años, nosotros también siempre juntábamos túnicas para los niños, calzados, siempre anduvimos en lo social. Hoy como Alcaldesa ayudamos a 300 familias muy carenciadas para que tengan un mejor nivel de vida, todo lo que era de choza o de lata, tratamos de darle el material, tanto bloque como chapa, como piedra, todo para que tengan una mejor calidad de vida y que no vivan como vivían, eso lo hicimos con más de 300 familias. (Mary Urse)}

Em compensação, cinco mulheres da FA relataram que iniciaram a trajetória política muito jovens, militando na clandestinidade durante o período autoritário. Destacamos a fala de Mabel Lamadrid (FA), militante do Partido Socialista, setor que atualmente compõe a FA. Afirma que "durante toda sua vida esteve vinculada à atividade sindical" e, que com o retorno à democracia passou a militar pela FA, agora de forma pública. Durante a entrevista, a líder sindical relembrou alguns momentos que viveu na ditadura militar e que marcaram sua trajetória:

[...] Estuve detenida en la dictadura, en el 1974 yo trabajaba en una fabril textil - la CMT, que es hoy CNT - en ese momento hizo un paro, un apagón en toda la fábrica. Nosotros lo hicimos, además yo era la delegada, la que estaba visualizada por la empresa, apagamos las luces y bueno, después me 
Rosangela Marione Schulz e Marina dos Santos Landa

\begin{abstract}
detuvieron primero 15 días. Después en el 1977 me volvieron a detener por un mes y después en el 1982 me volvieron a detener también por dos meses. Buenas, viví todo ese tema de la dictadura de terror porque nunca sabías cuándo te podían llevar y trabajabas en un lugar y sabías que al poco tiempo ya sabían dónde estabas. (Mabel Lamadrid)
\end{abstract}

As três mulheres mais jovens do grupo de eleitas pela FA, Adriana Rojas, Lilián Piña e Susana Camarán, mencionaram que sua relação com partidos políticos, em especial com a Frente Ampla, estreitou-se a partir do retorno da democracia em 1984. Além disso, as três declararam que há muitos anos estão envolvidas em atividades ou cargos relacionados com a descentralização em Montevidéu, participando ativamente de mobilizações nos bairros, representando a localidade em que residem. Rojas explicou que:

[...] Yo fui Concejal Vecinalxiii durante 10 años en la zona del Cerro, o sea, que yo tenía experiencia en la descentralización. Concejal Vecinal 10 años y también militante política, cuando se armaron los municipios dentro de la zona del Municipio yo participé de las discusiones (Adriana Rojas).

Em contrapartida à longa militância das frenteamplistas, duas nacionalistas mencionaram que a filiação ao partido era algo recente. É o caso de Beatriz Lamás (PN) e de Gletel Ferrari (PN), que se filiaram especificamente para concorrer ao pleito de 2010.

[...] Soy afiliada al partido desde ahora, pero he sido siempre del Partido Nacional, siempre voté al Partido Nacional, siempre por un tema también familiar, de historia, viste, la divisa blanca, la línea de mi familia era de los caudillos blancos, entonces yo seguí la línea familiar de mi padre, era activo en el partido, me llevaba de chiquita a la casa del partido, entonces yo quedé en el partido, siempre me gustó el partido nacional y nunca me cambié, tengo una identidad de familia. (Beatriz Lamás)

Rosa Imoda (PN) destacou sua ligação e seu trabalho como secretária pessoal de Luis Lacalle Pou xiv: "Hace 15 años que militamos juntos. Con Lacalle Pou, incluso yo fui su secretaria en el Parlamento, cuando fue Diputado". Graciela Echenique (PN) ressaltou que é tradicionalmente de família blanca, milita no partido desde muito jovem e inclusive um irmão seu - já falecido - havia sido Intendente de Cerro Largo. Em 2005, trabalhou para o Intendente do Cerro Largo, que impulsionou sua candidatura em 2010.

[...] Yo milito políticamente desde mi adolescencia en la lucha contra la dictadura, porque nosotros tuvimos aquel proceso de dictadura y en mi época de estudiante en Montevideo allí empecé a militar, pero tengo una fuerte influencia Blanca (Partido Nacional). Mi familia es Blanca, soy Blanca por convicción y por tradición, las dos cosas, después estuve siempre en el área social, trabajé mucho en el área social de manera independiente, pero siempre militando dentro del Partido, yo trabajé para mi hermano que fue también Intendente en un periodo acá, falleció muy joven en un accidente. Después trabajé para el actual Intendente de Cerro Largo, para Sergio Botana, bueno ahí en esa militancia a él se le ocurrió que yo podía sacar una lista, bueno saqué esa lista y la verdad nos fue muy bien. (Graciela Echenique) 
Rosangela Marione Schulz e Marina dos Santos Landa

Pode-se perceber que as mulheres da FA têm uma larga trajetória de militância e envolvimento com trabalho social. As mulheres do PN, embora não tenham exercido cargos ou militância política, também possuíam identificação partidária, tendo relações familiares ou pessoais com quadros importantes do partido.

A partir das narrativas, identificamos também como ocorreu o recrutamento partidário para disputar as eleições. No Departamento de Montevidéu, em quase sua totalidade, as entrevistadas comentaram que sua inscrição como candidata ocorreu por terem sido envolvidas com o processo de descentralização existente na cidade, desde a criação dos Centros Comunales Zonales (CCZ's) ${ }^{x v}$. Adriana Rojas (FA), Lilián Pinã (FA), Teresa Nieves (FA) e Susana Camarán (FA) talvez sejam as mulheres que mais se enquadram nesse movimento. Em suas falas, comentaram que o recrutamento aconteceu em decorrência das atuações no âmbito local. Adriana Rojas (FA) explicou que:

\section{[...] Yo tenía conocimiento, entonces mi sector me propuso para estar integrando la línea, que yo en realidad estoy en la línea del Alcalde, viste que son cinco líneas, yo estoy con el Alcalde, en el mismo sector político. Entonces digo, fue como definición de los compañeros del territorio del MPPxi armar la línea para la lista y en esa línea por la experiencia y la militancia social, entre yo también. (Adriana Rojas)}

Cabe destacar que os relatos apresentados sobre a atuação nos CCZ's, encontram respaldo na reflexão da literatura uruguaia. Moreira destaca que as mulheres sempre foram mais atuantes na esfera local, em especial nos bairros onde vivem. Considerado um espaço periférico, é determinante para que as mulheres começassem a compartilhar da experiência de tomada de decisões. "Allí la participación femenina adquiere un espacio y una importancia considerables" (MOREIRA, p.112, 1994). Da mesma maneira, ao analisar a presença feminina nos CCZ's em 1996, Johnson observou uma participação maior de mulheres do que em qualquer outro nível institucional "Casi una tercera parte de los concejales (29,3\%) eran mujeres, había siete presidentas (38,9\%) y cinco secretarias $(27,8 \%)$, y tres de los dieciocho Consejos Vecinales tenían más de un cincuenta por ciento de delegadas" (JOHNSON, 2001, p.76). Desta forma, desde a década de 1990 proliferavam em vários bairros organismos locais e comissões de bairro, ambiente que possibilitou às mulheres exercitar a prática política e transitar nos espaços de decisão.

Um caso particular foi o recrutamento de María Elena (FA), oposto ao de todas companheiras da FA. Segundo seu relato, o convite foi feito "às pressas", devido à dificuldade de ajustar nomes nas listas e a limitação de tempo para isso.

\section{[...] Yo solo quería decir que en mi caso fue mi grupo político que me impulsó digamos. Yo estaba viajando y llamaron por teléfono, ni sabían que yo estaba en España, me llamaron para una consulta si podían manejar mi nombre para el municipio. Yo les dije que había salido de la junta local y que no quería saber más nada. Pensé un segundo y les dije: hagan lo que quieran con mi nombre y cuando vaya me entero! No me dieron tiempo a pensar, pero no me arrepiento! (María Elena}

Miríam Rodríguez (FA), Mabel Lamadrid (FA) e Cristina Oliveira (FA) alegaram que a decisão se originou das combinações e acordos traçados internamente pelos setores que compõem a FA, coube a elas assumir o compromisso como militantes partidárias. Sob essa perspectiva, Sandra Nedov (FA) foi ainda mais incisiva na questão da militância partidária. 
Rosangela Marione Schulz e Marina dos Santos Landa

Segunda a A/caldesa do Município D explicou, os militantes deveriam estar à disposição, deveriam entender as necessidades do partido, que estão acima das exigências individuais:

[...] Bueno, nosotros somos la militancia política. El partido político es quien dice a dónde deberíamos ir, yo no me postulo, yo no pretendo estar en un lugar, las agrupaciones de cada zona eligen al compañero que se propone, eso va al partido político, el partido político apoya esta figura, no es una decisión propia. Yo, por ejemplo, ahora puedo ser reelecta, no sé si voy a ser reelecta, no sé si me van a proponer para eso o para otra cosa, integró la lista o soy convencional de mi partido. Pero, después, nosotros estamos a disposición de que el partido diga "bueno te necesito en tal lugar" y ahí tenemos que ir, a mí en particular me gusta más desempeñar cargos ejecutivos que legislativos, pero, si tengo que ser legislativo, pues bueno! (Sandra Nedov)

No Departamento de Canelones, a A/caldesa de Progreso, Cristina Castro (FA) creditou sua candidatura a experiência na Junta Local do departamento canário. Além disso, ela destacou os 57 anos de residência na localidade:

Para concurrir al cargo es electivo, entonces diferentes sectores a nivel del departamento tenían sus candidatos, incluso dentro del Frente mismo, competimos internamente. Bueno, salió nuestra lista la más votada. Como dice la Ley 1567, la lista y el lema más votado, el primero de la lista sería el Alcalde y los demás en la lista los concejales, son cuatro más. Al ser Edil Departamental me propusieron y estaba dispuesta, tenía que tener por lo menos tres años viviendo en la localidad, yo tenía más de tres de años, yo tengo 57. (Cristina Castro)

A mais de 300 quilômetros da Capital, no Departamento de Rocha, Mary Urse (FA) também creditou seu recrutamento ao reconhecimento dos cidadãos, em especial do bairro onde realiza trabalhos comunitários,

[...] Porque el Barrio Samuelxvii, fue más bien quien me hizo líder de ese barrio, le gustaba lo que yo trabajaba, trabajamos por siete años en esa comisión y no descansábamos nunca y fue en ese mismo barrio que me hice líder y de ahí la presencia en la Junta Local y hoy Alcaldesa. (Mary Urse)

Enquanto nas narrativas da FA a relação com a comunidade local foi determinante na grande maioria dos caso para o recrutamento, três das entrevistadas nacionalistas citaram que a convocação aconteceu por indicação partidária. No caso de Graciela Echenique (PN), Alcaldesa de Fraile Muerto, a ideia partiu do Intendente de Cerro Largo em exercício na época,

[...] Si, fue el partido, yo no. Yo en todos los años de militancia, militaba digamos buscando votos, hablando con la gente, haciendo puerta a puerta, socialmente, pero nunca jamás se me había ocurrido sacar una lista. En realidad la idea fue del actual Intendente, de Sergio Botana, que me pidió que sacara una lista. Yo en ese momento ya tenía mis hijos grandes, al ser yo bastante tradicional en mi vida, crianza de hijos, matrimonio, todas esas cosas, pues podía dedicarme verdaderamente porque tenía tiempo suficiente como para 
Rosangela Marione Schulz e Marina dos Santos Landa

dedicarme a la política, bueno y así fue porque esto lleva tiempo, mucho tiempo. (Graciela Echenique)

As outras duas Alcaldesas impulsionadas por padrinhos são Beatriz Lamas (PN) e Rosa Imoda (PN), eleitas no departamento de Canelones, ambas mencionaram a indicação de Luis Lacalle Pou. Além dessa relação, Lamas destacou que o partido propôs sua candidatura por ela ser mulher:

[...] El partido me propuso, Luis Lacalle Pou eligió más o menos un perfil profesional, eligió en casi todos lados una mujer, si tenía una mujer en vista y como yo votaba la agrupación, él sabía que yo era del partido me propuso ir, yo no sabía si aceptarlo, ya acepté y ya quedé. (Beatriz Lamas)

A partir da análise dos trechos selecionados, concluímos que a identificação partidária também implica em diferenças no tocante ao recrutamento partidário. Percebemos que as mulheres da FA compartilham um sentimento de militância que as impulsionou a aceitar a convocação de sua instituição partidária. Em relação ao recrutamento realizado pelo PN é possível observar que o partido estabeleceu um perfil político para convocar suas candidatas e a partir disso, o convite foi oficializado.

No terceiro eixo, veremos que, como aconteceu nesta sessão, a ideologia partidária interfere no posicionamento das entrevistadas frente às opiniões sobre o funcionamento dos governos locais. As mulheres da FA demarcaram falas mais entusiasmadas, ressaltando o ato de descentralizar o poder e queixaram-se da adesão popular, observando que seu reconhecimento depende muito do trabalho executado. Enquanto isso, as mulheres do PN fizeram grandes críticas ao conteúdo da lei, denunciaram a falta de autonomia e de recursos para executar ações nos municípios, embora também tenham apontado algumas conquistas.

Beatriz Lamas (PN) reforçou que as mudanças têm sido lentas, sobretudo que faltam muitos atributos e recursos, essa escassez impossibilita a contratação de funcionários, exigindo muita dedicação dos Alcaldes para o pleno funcionamento dos municípios,

[...] Realmente lo hago porque me gusta, me gusta la tarea, pero falta descentralización, demasiado lento, faltan recursos y la gente, la población por lo menos en los lugares chicos le atribuye todo al Alcalde, todo los temas, temas que no son de potestad del alcalde también, eso lo hemos visto, por ejemplo acá en San Ramón. (Beatriz Lamas)

Da mesma maneira, Gletel Ferrari (PN), Rosa Imoda (PN) e Graciela Echenique (PN) traçaram críticas ao conteúdo específico da lei, queixaram-se da pequena autonomia perante as Intendências, da limitada verba que os municípios recebem. Por fím, mencionou as mesmas lacunas que as outras já haviam destacado. Lembrou que há muito para se avançar, principalmente sobre a captação de recursos,

[...] En estos primeros años de descentralización sigue siendo dependiente del gobierno departamental, no tenemos recursos propios, hasta creo que lo que más hemos logrado es ver cómo impacta el gobierno local, ver que es el gobierno local, ver que hay que seguir avanzando en la descentralización, no perder de vista la parte de desarrollo local, pero nos falta avanzar mucho sobre todo la parte de recursos y ver realmente cómo quedan los recursos, si se nos va dar un porcentaje de recursos de los recaudados, regionalizar 
Rosangela Marione Schulz e Marina dos Santos Landa

los recursos también, la micro-región, tampoco es superponer recursos y no sub-utilizarlos, es tener los recursos necesarios y que sean bien utilizados, porque tampoco sirve tener maquinaria para que trabaje una semana en un mes, entonces eso creo que se debería articular con la región. Bueno, vamos andando. (Graciela Echenique)

As opiniões das mulheres da FA também se aproximaram muito neste quesito. Cristina Castro (FA), que está fora das zonas de Montevidéu, foi quem mais teceu críticas ao teor da lei aprovada em 2010. Segundo suas análises, a lei menciona apenas uma "desconcentración de poder", entretanto, adverte que se deve buscar uma verdadeira descentralização dos municípios, mais autonomia perante as Intendências. Lilian Piña (FA) fez questão de lembrar que a descentralização política existe em grande parte pela mobilização do governo nacional:

[...] Yo creo que la gente se olvidó de cómo vivíamos antes, antes del gobierno del Frente Amplio [...] No es como ahora, que es fácil, que te abran la puerta de un ministerio que están abiertos para escuchar a la gente, los ministros bajan más a hablar con la gente. Están muy próximos a la gente, andan haciendo recorridos por los barrios, vienen a las ferias. Los senadores, se ocupan mucho de la gente, incluso dan charla en los comités de base y en casas de familias. El domingo tuvimos la recorrida del candidato por la zona y fue un mundo de gente que iba en la recorrida, hablando con los vecinos del proyecto de gobierno, con la participación de las organizaciones de base, del consejo vecinal donde se reúnen. Nosotros hacemos todos los años un cabildo abierto donde rendimos cuentas de lo que se hizo en ese año, donde se invirtió la plata de los fondos que vinieron de la intendencia, en que se invirtió, en obras, en podas, en mantener plazas públicas, la electricidad, la luz, todo eso se vuelca en el cabildo abierto. (Lilián Piña)

Adriana Rojas (FA) se utilizou de uma metáfora para explicar como acontece o trabalho municipal: "trabalho de formigas". Isto é, trata-se de um trabalho contínuo, lento e coletivo. Também ressaltou a criatividade que o Conselho deve ter para realizar suas atividades e atingir os objetivos propostos pela lei. Miríam Rodríguez (FA) advertiu que nesta primeira etapa ainda há muitos aspectos para serem corrigidos, contudo, ressaltou positivamente a riqueza de ter um governo próximo ao cidadão e a obstinação da equipe municipal que atua em conjunto,
[...] El gobierno de cercanía lo que te da es la riqueza del conocimiento del problema del vecino en forma directa, conforme o disconforme, reclamo o felicitación pero tienes ese contacto en forma directa. Es la primera experiencia en el país y estamos haciendo todo un aprendizaje de esta nueva etapa del proceso, es un equipo y unos funcionarios muy comprometidos con el proceso y creo que eso nos ha ayudado enormemente a que sea más sencillo. (Miríam Rodríguez)

A Alcaldesa Mary Urse (FA) seguiu a mesma linha de Miríam Rodríguez, embora também tenha reconhecido os cortes orçamentários por parte da Intendência, considerou que sua administração tem sido exitosa: 
Rosangela Marione Schulz e Marina dos Santos Landa

[...] Nosotros hicimos presupuesto que fue votado y todo, en el presupuesto nos quedamos cortos, pero salimos muy bien igual y ya aprendimos para el outro. El presupuesto no es propio, la Intendencia nos manda 620 mil pesos por mes, com eso nos tenemos que manejar en todo, pagar los obreros y empleados. Pero la administración ha sido un éxito, el otro día vinieron de Montevideo, hicieron un arqueo y fueron a felicitarme delante de todos los concejales. (Mary Urse)

Mabel Lamadrid (FA) também reconheceu que os recursos destinados ao seu município são insuficientes, entretanto fez questão de mencionar que até poderia haver outras formas de captar recursos, restando analisar o que a Lei permite. Além disso, fez questão de comentar sobre a autonomia dos municípios para gerir os recursos que lhes são destinados, segundo a mesma, este é o grande triunfo:

[...] La Intendencia departamental asigna a los municipios un dinero del presupuesto que siempre es menos de lo que el municipio precisa. A su vez, también, hay posibilidades que creo que ningún municipio lo ha hecho todavía, que es recibir donaciones de acá como del exterior como dice la ley, todavía no está muy claro cómo se pueden recibir estas donaciones porque los municipios no tienen personalidad jurídica. Es complejo porque es algo que recién comienza en la historia política de un país, cuatro años no son nada, pero lo bueno de todos los municipios de éste y de los ocho en total, es que todos han podido ejecutar cada año el presupuesto que tuvieron. (Mabel Lamadrid)

Com outro olhar, Susana Camarán (FA) resgatou suas memórias e contou como foram os primeiros dias de governo, e como o corpo político eleito conseguiu se organizar perante tantos desafios, e expôs a evolução nestes cinco anos. Por fim, terminou sua fala de forma bastante otimista, ressaltando o crescimento da popularidade municipal e o reconhecimento dos moradores na região,

Que fueron seis meses sin presupuesto, seis meses en que teníamos que planificar el plan de desarrollo para cinco años, el presupuesto del año siguiente, la presentación ante la Junta y ante los vecinos, seis meses sin un peso, los vecinos pedían barrido, pero teníamos ni un peso ni gente, ni maquinaria, fue terrible. [...] Hoy los ocho municipios somos capaces de llevar adelante un presupuesto, capaz de entender todas las reglas de funcionamiento del Estado, de relacionarnos bien con los vecinos de poder avanzar en la gestión, estamos muy involucrados con la gestión y ha quedado poco tiempo para la política, las decisiones son políticas también, transmitirle al vecino el porqué de las decisiones. (Susana Camarán)

Por fim, Teresa Nieves (FA), ressaltou o contato com a população. Assim, a entrevistada apresenta um resumo de como a atividade política tem se dado em seu cotidiano: 
Rosangela Marione Schulz e Marina dos Santos Landa

expedienta acá se transformó en una cara visible porque si el vecino tiene un problema del árbol, de la luz, de la calle, viene y nos pide una entrevista, o vemos el expediente a ver que falta en una calle, fue como humanizar ese expediente que en la centralización no pasaba. (Teresa Nieves)

A partir dos comentários das entrevistadas é sensível perceber que o projeto de descentralizar a estrutura política foi iniciativa do programa de governo nacional da FA. Assim, as mulheres da FA defenderam a proposta aprovada, ressaltaram a importância de seu partido para que a lei fosse institucionalizada. Elas também clamaram pela ampliação da participação popular, mencionando que a política local depende da boa relação com os cidadãos. Diversamente, as mulheres do PN fizeram críticas consideráveis ao funcionamento dos municípios, ressaltando a falta de recursos para a realização de obras, revitalização das cidades e o pagamento do corpo de funcionários. Também queixaram constantemente da dependência política perante as Intendências, lembrando que precisavam negociar caso quisessem realizar algum projeto

O terceiro eixo da entrevista também indagou sobre a ambição política das eleitas. Observamos que em vários depoimentos as mulheres relataram dificuldades para dar seguimento a sua carreira política. Duas mulheres mencionaram que não pretendiam seguir a carreira institucional porque desejavam se dedicar a família. Gletel Ferrari (PN) relatou que se tornou complicado conciliar as atividades do Conselho Municipal com as atividades de sua profissão. Além disso, advertiu que gostaria de se fazer mais presente no desenvolvimento do filho,

[...] No, mucho trabajo. No porque no esté interesada, no porque no me guste, o porque no me haya dejado muchas satisfacciones en general y en lo personal, pero, bueno, uno tiene que elegir. Voy a seguir con la medicina y no puedo seguir con esto porque esto requiere mucho tiempo. Es lindo pero cansa, mucho trabajo y uno está muy expuesto por los dos lados, como médico y como gobierno local también. Digo que como que cansa, como madre uno tiene también que estar presente, tengo un hijo adolescente de 16 años, hay que estar. (Gletel Ferrari)

María Elena (FA) atribuiu à sua decisão de se aposentar as questões da idade, embora tenha admitido que seguirá militando pelo partido, mas não em um cargo eletivo. Além disso, também mencionou seus compromissos familiares:

[...] Mi partido ya me lo planteó y yo dije que bajaba un escalón, voy a seguir trabajando, militando, pero no de forma en el municipio como integrante, porque tengo 67 años y tengo una nietica de dos y quiero tener más tiempo, además quiero ayudar a mi hija. (María Elena)

Seis entrevistadas não souberam responder ao questionamento. Todas às mulheres filiadas a FA, revelaram que esta é uma decisão que cabe ao partido. Nesse sentido, Teresa Nieves foi breve, porém contundente "[...] No sé, según lo que diga lo partido". A mesma postura adotaram Míriam Rodríguez, Cristina Oliveira e Susana Camarán em suas respostas, entretanto elas reafirmaram o compromisso com o projeto municipal, colocando-se totalmente à disposição do partido. 
Rosangela Marione Schulz e Marina dos Santos Landa

Amplio decida, fui representante del comité de base de la coordinadora, fui representante de la coordinadora en la 41, fui representante del 41 en el partido, fui al Congreso pero el Frente Amplio siempre decidió. Yo estoy dispuesta a ir si mi partido me pone ahí pero no lo defino yo, lo definen otros. (Susana Camarán)

Sete mulheres afirmaram que gostariam de continuar na política a nível municipal, por que gostam da dinâmica local xviii. Sendo que três entrevistadas, Mary Urse (FA), Graciela Echenique (PN) e Beatriz Lama (PN) manifestaram claramente desejo em buscar a reeleição. Mary Urse (FA) incluiu em sua reflexão problemas enfrentados por ser mulher, por não condizer com os padrões socioeconômicos. Porém, destaca o apoio para a superação dessas adversidades.

[...] Al principio tuvimos muchos problemas, por el hecho de ser mujer, el hecho de no tener bachillerato, pero hicimos los que otros no han hecho y son abogados. Ahora la gente me apoya y la familia me apoya mucho, los concejales también. [...] Así, el 10 de febrero renunció para poder ser reelecta en Mayo, el 10 de mayo son las elecciones. (Mary Urse)

Por fim, Mabel Lamadrid (FA), explicou que apesar da sua idade, possui grande disposição para continuar atuando politicamente, destacando o benefício que a aposentadoria Ihe proporcionou para sua permanência na vida pública.

[...] Bueno, la elección del 2015 en realidad en mi partido los candidatos y candidatas se eligen en una Convención Departamental, y en la última convención departamental en las elecciones que se hicieron yo quedé en la lista de ediles y edilas en séptimo lugar, que también acá en éste país los ediles y edilas son honorários. Bueno, después están las suplencias que se tienen que armar porque se eligen los primeros y segundo lugares nada más, los terceros y cuartos suplentes quedan a definir después. Entonces la idea es seguir para poder aportar, yo ya tengo 60 años, pero tengo mucha energía y ahora además que jubile, o sea, que tengo más tiempo para dedicar a la militancia, entonces la idea es seguir aportando, no sé en el municipio, todavía no está muy claro cómo van a ser las elecciones, si por lista o una lista única, todavía no sabemos. (Mabel Lamadrid)

Ao apresentar as falas das mulheres que não pretendem concorrer à reeleição, foi possível perceber que a decisão tem implicações de gênero. As duas mulheres desistentes citaram o anseio de se dedicar à família e a dificuldade de conciliar a vida pessoal com a atividade política, tema constante na literatura que trata dos obstáculos à participação das mulheres no campo político eleitoral. Conforme Pérez (2006),

El tiempo disponible es un aspecto relevante al momento de analizar la cantidad de mujeres en política porque si bien no influye directamente, sí opera de manera indirecta. Este aspecto, se relaciona con quiénes se encargan de la realización de las tareas domésticas. Es decir, si son las mujeres las principales encargadas de esas actividades -además del tiempo que les insuma el trabajo remunerado- entonces el tiempo disponible para el activismo será menor. Y, dado que la carrera hacia un cargo político implica no sólo poseer determinadas cualidades, sino también invertir gran cantidad de tiempo en las actividades del partido, es razonable concluir que las mujeres podrían hallarse en desventaja en este aspecto. (PÉREZ, 2006, p.4).

Socialmente as mulheres enfrentam grandes obstáculos para dedicar-se a carreiras ou projetos pessoais por acumularem funções atreladas à esfera privada. Na situação das entrevistas significa manter mais uma jornada de atividades, para além das tarefas que tradicionalmente se ocupam. As narrativas das representantes entrevistadas deixam transparecer que, apesar das divergências apresentadas, dedicar-se ao trabalho municipal 
Rosangela Marione Schulz e Marina dos Santos Landa

custa-Ihes tempo e energia. Logo, desempenhar uma atividade junto ao Conselho Municipal é algo que toma o tempo que antes dedicavam a outras esferas de suas vidas, como a laboral e a familiar, por isso, algumas mulheres se veem obrigadas a fazer escolhas. Da mesma forma que o tempo é um obstáculo para desempenhar as funções públicas, também é um entrave na participação em espaços masculinizados, como é a esfera política em geral.

\section{Considerações finais}

Dentre os resultados encontrados, o primeiro aspecto que cabe destacar é que há uma distinção entre os caminhos percorridos pelas mulheres da FA e pelas mulheres do PN até chegarem como candidatas vitoriosas nas eleições municipais. A identificação partidária, dentro da amostra, se mostrou como balizador e, por isso, determinante no exame de cada ponto apresentado.

Em relação ao perfil socioeconômico, há apenas dois aspectos em comum dentre todas as entrevistadas: as variáveis idade e constituição familiar. Em resumo, são mulheres maduras e com famílias já constituídas. Por outro lado, em relação à escolaridade, não foi possível encontrar um padrão nas respostas, o que sugere uma fraca correlação entre a variável e o resultado eleitoral. $\mathrm{Na}$ análise das profissões o destaque é para a diferenciação de atividades laborais das frenteamplistas e das nacionalistas. No primeiro caso, as mulheres exercem majoritariamente profissões endógenas à política, enquanto no segundo se dedicam a profissões liberais.

No que concerne ao segundo eixo, isto é, sobre o exercício da militância e a construção da trajetória política, também convêm salientar a existência de um padrão distinto entre as mulheres filiadas a FA e aquelas filiadas ao PN. Dessa forma, todas as mulheres da FA relataram um histórico atrelado aos movimentos sociais e/ou sindicatos e mencionaram um passado de longa militância partidária, a grande maioria exercia a militância a nível local. Ao contrário, as mulheres do PN afirmaram ter estreitado seus vínculos partidários somente para a disputa eleitoral (duas delas filiaram-se com esse propósito específico). Nesse sentido, três mulheres tiveram suas candidaturas impulsionadas por padrinhos políticos em 2010.

Todas as mulheres têm em comum o fato de serem iniciantes na esfera política institucional, ou seja, ainda estão em fase de construção da carreira pública, porém já praticavam em algum tipo de ação política no seu cotidiano. Assim, é possível compreender o terceiro nível de governo como um espaço para penetrar no campo político tradicional, um espaço novo, com regras institucionais diferentes e atores políticos ainda em desenvolvimento.

As entrevistas permitiram conhecer algumas das percepções dessas mulheres sobre a condução de um governo voltada para a atuação local, no qual se almeja a participação popular na tomada das decisões. Primeiramente, se deve mencionar que todas avaliaram a atuação a nível local como um movimento de extrema necessidade na política do Uruguai. Não foi raro nas entrevistas a menção de que o terceiro nível de governo deveria ser considerado o "primeiro nível de governo", pois, invertendo a lógica, esse seria o principal contato dos cidadãos com os representantes. Todas salientaram que há muito trabalho pela frente e destacaram a importância de lidar diretamente com população.

Durante a execução das entrevistas, observou-se a formação de dois discursos políticos distintos. Essa polarização ideológica partidária entre FA e PN aparece em todos os 
Rosangela Marione Schulz e Marina dos Santos Landa

pontos das entrevistas. Isto é muito claro quando as respostas são analisadas coletivamente. Para além, embora não estivesse presente no questionário, surgiram críticas à forma como o governo nacional da FA estaria conduzindo o país, como a "liberdade" estaria sendo confundida com "desordem", relatadas pelas militantes do PN. Em relação a outros conteúdos expostos nas entrevistas, é importante ressaltar as memórias das frenteamplistas com mais idade a respeito da repressão e da resistência à ditadura militar, tanto quanto seus envolvimentos em greves gerais e seus ativismos em movimentos sindicais.

Os depoimentos colhidos demonstram a percepção das mulheres que estão à frente de cargos recém criados. Acreditamos que as entrevistas permitiram compreender, a partir do olhar das próprias atrizes políticas, possibilidades e limites da atuação política de mulheres no momento de construção de um novo espaço de poder em âmbito local. Assim, a partir da interseção da teoria política feminista e do trabalho empírico, debruçamos a atenção em trajetórias de militância de mulheres em pequenas localidades, que, contornando as restrições de gênero, adentraram com sucesso eleitoral a esfera pública da política, uma condição tão cara às mulheres em democracias representativas liberais.

(Recebido para publicação em agosto de 2019)

(Reapresentado em setembro de 2019)

(Aprovado para publicação em dezembro de 2019)

\section{Cite este artigo}

SCHULTZ, Rosangela; LANDA, Mariana, 2019. Mulheres em municípios no Uruguai: o perfil, a trajetória e as experiências das alcaldesas e concejalas eleitas no país (2010-2015). Revista Estudos Políticos: a publicação semestral do Laboratório de Estudos Hum(e)anos (UFF). Rio de Janeiro, Vol.10 | N.2, pp. 198- 219, dezembro de 2019.

\section{Notas}

1. O Poder Executivo é exercido pelo Presidente da República e pelo Vice-Presidente, atuando juntamente com os ministérios. O Parlamento é dividido em Senado com 30 membro e Câmara de Deputados com 99 cadeiras.

2. Cada Departamento (Estado) é governado por um Intendente (Governador) e por uma Junta Departamental, composta por 31 deputados, denominados Ediles Departamentales.

3. O cargo Alcaldesa corresponde ao cargo de Prefeita no Brasil. Porém, a tradução direta de Concejala para Vereadora não é tão tranquila, talvez Conselheira seja a expressão mais indicada, já que trata-se de um 
Rosangela Marione Schulz e Marina dos Santos Landa

cargo não remunerado no Uruguai no qual aconselhar parece ser a função maior. Preferimos então, respeitando as particularidades do idioma, manter os cargos no original em espanhol.

4. Os Conselhos Municipais são compostos pelos candidatos/as eleitos/as para os dois cargos, como será melhor explicado em seguida.

5. A representação feminina no Parlamento Uruguaio manteve-se muito baixa em 2009 alcançando 15,1\%. Na classificação mundial de mulheres nos Parlamentos o Uruguai ocupava a 104a posição (15 deputadas federais em 99 - eleições 2009). Em relação às eleições departamentais, realizadas juntamente com as eleições municipais, foram eleitas apenas três mulheres para os cargos departamentais (deputadas estaduais), correspondendo a $15,7 \%$.

6. De acordo com a Lei de Descentralização Política e Participação Cidadã, todos os alcaldes que almejassem disputar a reeleição deveriam renunciar ao cargo em fevereiro de 2015, por isso, a grande maioria das autoridades entrevistadas já estava refletindo sobre 0 período de seu mandato.

7. Vale lembrar que nesta eleição a FA foi eleita pela primeira vez para assumir a presidência do país, derrotando o bloco tradicional formado pelo Partido Nacional (PN) e pelo Partido Colorado (PC).

8. Em 2020 o país viverá sua terceira eleição municipal, o primeiro ciclo eleitoral corresponde ao período de 2010-2015 e o segundo ciclo eleitoral corresponde ao período de 2015-2020, ou seja, a experiência municipal está completando dez anos no país.

9. Os municípios devem apresentar o Plano Municipal de Desenvolvimento e propor o orçamento para os próximos cinco anos, bem como os respectivos ajustes anuais, após a realização de assembléia com a comunidade local.

10. Ademais, define que a composição dos Conselhos Municipais será pela via eleitoral, isto é, todas as autoridades são escolhidas por um pleito eleitoral, de forma eletiva.

11. Partido Blanco é nome de fundação do Partido Nacional. Sua origem, assim como o do Partido Colorado, remonta ao início do século XIX, sendo que a criação da agremiação política é anterior a própria consolidação da República e da primeira Constituição uruguaia.

12. Anteriormente a criação dos municípios, o ordenamento jurídico do país previa a criação de 
Rosangela Marione Schulz e Marina dos Santos Landa

Juntas Locais, de administração coletiva, composta por cinco membros, não remunerados. A criação destes organismos dependia da vontade do Intendente que nomeava as autoridades locais, estas pessoas recebiam a designação de Edis Locales.

13. Os Consejos Vecinales constituíam-se em organizações locais anteriores aos municípios, que buscavam reunir os atores sociais dos bairros em Montevidéu. A organização em Centros Comunales Zonales (CCZ's) possibilitou protagonismo local aos agentes para definir quais eram as principais carências e necessidade de cada zona do Departamento.

14. Luis Lacalle Pou, atual Presidente da República Oriental do Uruguai (2020-2025), filho do expresidente Luis Alberto Lacalle, sendo um dos principais quadros do Partido Nacional.

15. Os Centros Comunais Zonais (similares aos Centros Comunitários encontrados no Brasil) eram dependências descentralizadas da Intendência de Montevidéu, responsáveis pela gestão administrativa, procedimentos, reclamações, solicitações e serviços. Com a municipalização, os 18 CCZ's foram agrupados dentro dos oito municípios do Departamento.

16. O Movimiento de Participación Popular (MPP) é um grupo político da esquerda uruguaia, fundado por exguerrilleros do Movimiento de Liberación Nacional Tupamaros. O MPP forma parte da coalizão de esquerdas Frente Ampla.

17. O Bairro Samuel Priliac é uma das localidades mais carentes do Município de Chuy. Dentre as atividades que desenvolve no bairro, Mary Urse organiza anualmente a festa do Dia de Reis, 6 de Janeiro, sendo responsável pelas doações e distribuição de brinquedos e materiais escolares.

18. As três mulheres que mencionaram que gostariam de continuar no cargo de Alcaldesa foram reeleitas e tiveram seus mandatos ampliados para o segundo ciclo municipal (2010-2015).

\section{Referências bibliográficas}

BARRETO, Álvaro Augusto de Borba. Criação de municípios no Uruguai (2009 2010): processo de inovação institucional. Revista Jus Navigandi, 2011, vol.16, no 2940, pp.1-2.

JOHNSON, Niki. Las cuotas en Uruguay: uma medida resistida. In: ARCHENTI, Nélida; TULA, Mária Inés (Eds.). 
Rosangela Marione Schulz e Marina dos Santos Landa

Mujeres y política en América Latina: sistemas electorales y cuotas de género. Buenos Aires: Heliasta, 2008.

JOHNSON, Niki. ¿Democracia a medias? La representación de la mujer en cargos políticos electivos en Uruguay, 1984-1994. Revista Uruguaya de Ciencia Política, 2001, n012, pp. 69-96.

JOHNSON, Niki. La política de la ausencia: las elecciones uruguayas 2004-2005, las mujeres y la equidad de género. Montevideo: CNS Mujeres por Democracia, Equidad y Ciudadanía. 2005.

LANDA, Marina dos Santos. Participação feminina no terceiro nível de governo uruguaio: o perfil das Primeiras Alcaldesas e Concejalas eleitas aos Conselhos Municipais (2010-2015). 2015. 114 f. Dissertação (Mestrado em Ciência Política) - Programa de Pós-Graduação em Ciência Política, Instituto de Filosofia, Sociologia e Política. Universidade Federal de Pelotas, Pelotas, 2015.

MAGRI, Jessica Altair. FREIGEDO, Martín. Municipales 2010: ¿elecciones de segundo orden? In: BUQUET, Daniel.; JOHNSON, Niki (Org.). Del Cambio a la continuidad - ciclo electoral 2009-2010 Uruguay. Montevidéu: Fin de Siglo/Clacso/Instituto de Ciencia Política, 2010, pp. 325-346.

MOREIRA, Constanza. Participación de la mujer en el sistema de toma de decisiones: en caso uruguayo. Revista Uruguaya de Ciencia Política. Montevidéu, 1994, n07, pp. 99-121.

OROÑO, Abel. Los Municipios en marcha. La descentralización local y los desafíos de su implementación. Montevidéu: Editora Friedrich Ebert, 2011.

PÉREZ , Verónica. Las mujeres en política en Uruguay. De la cuota a la paridad: una reforma necesaria. Universidad de la República, Uruguay. Policy paper n5, marzo 2015.

PÉREZ, Verónica; VAIRO, Daniela. Dime quién eres y te diré qué tan igualitario/a eres: Valores de género e implicancias para la participación política en Uruguay. Revista Debates. 2013, vol.7, no 1, pp.175-198.

PÉREZ, Verónica. $52 \%$ del Electorado, $11 \%$ del Parlamento: Factores Culturales y Representación Política Femenina en Uruguay. Revista Uruguaya de Ciencia Política, 2006, no 15, pp. 57-81.

QUETGLES, Raquel A.. La ausencia del territorio en la implementación de la política de descentralización en 
MULHERES EM MUNICÍPIOS NO URUGUAI: O PERFIL, A TRAJETÓRIA E AS EXPERIÊNCIAS DAS ALCALDESAS E CONCEJALAS ELEITAS NO PAÍS (2010-2015)

Rosangela Marione Schulz e Marina dos Santos Landa

Uruguay. Revista Geográfica de América Central, 2011, vol.2, no 47E.

SCHULZ, Rosangela e MORITZ, Maria Lúcia. Brasil e Uruguai: A difícil inclusão das mulheres no parlamento nacional (2009-2014). Anales del V Congresso Uruguaio de Ciência Política; Montevidéu, 2014, pp. 1-27. 